\title{
Deleuze and collaborative writing as method of inquiry
}

\author{
Dr Ken Gale \\ University of Plymouth, UK \\ Helen Bowstead \\ University of Plymouth, UK
}

\begin{abstract}
This paper is based on an interview with Ken Gale in which he talks about his experiences of collaborative writing and the ways in which Deleuzian concepts such as the 'rhizome', 'lines of flight', the 'nomad', the 'fold' and the 'body without organs' have informed and inspired his research and practice. The potential for how these concepts could help in offering a new cartography for learning development is also explored.
\end{abstract}

Keywords: learning development; Deleuze; lines of flight; the nomad; collaborative writing.

\section{Introduction}

In April 2013, Ken ran a Masterclass entitled 'Deleuze and Collaborative Writing as Method of Inquiry' at the $10^{\text {th }}$ ALDinHE conference held at Plymouth University. Participants were given the opportunity to engage in a range of writing activities and to critically reflect upon the use of collaborative writing as method of inquiry. Through the activities and subsequent discussions, Ken encouraged delegates to consider the potential of Deleuzian creative principles of conceptualisation and contextualisation to inform scholarly activity and pedagogic practice.

H: Yesterday I bought a copy of 'A Thousand Plateaus' (Deleuze and Guattari, 1988) I've dipped in and out of it over the years but I felt that the only way I was really 
going to engage finally with some of the more difficult concepts was if I owned a copy. So I thought we might just start by talking a little bit about some of the Deleuzian concepts that obviously have had such an impact on your own research and pedagogic practices. I thought we might start with 'lines of flight' because that's been a particularly liberating concept for me in my own professional writing.

K: I think it's a brilliant starting point because [A Thousand Plateaus] is such a fantastic compendium of ideas; literally you can take a 'line of flight' from one plateau to the next. I mean it's a book that doesn't really have linearity, so that makes it really exciting. It's the first book by Deleuze, or Deleuze and Guattari, which I bought; I've had it for over 10 years. I still go back to it and I'm blown away by bits in it that I never discovered before, or I go back to it and find something that I've heavily annotated and I see something different in it: I think it's a phenomenal book, I really think it would be my desert island book. I thought about how we would start this discussion and as you know, there are so many people, when they start talking about Deleuze, say they've got to start in the middle, because it's just so hard to know where to start. But in some respects it's so easy because you can start wherever you like. Elizabeth St Pierre talks about plugging in the ideas, which is great, it's just a simple idea, but I think from a learning point of view it is so emancipatory because for me the whole process of creating concepts, which [Deleuze] talks with Guattari (1994) about in 'What is Philosophy', is so much about student-centred learning, you can say to students, well what do you think, how do you conceptualise it?

$\mathrm{H}$ : I remember it being the point at which I felt confident enough to deal with Deleuze because I felt that if somebody like Elizabeth St Pierre could just say 'I don't really get it but I get something from it', then I could do the same.

K: Yeah absolutely, I've got something so therefore, let's do something with what l've got. And I think that's really powerful from a philosophical point of view but also in a pedagogical sense. I'm a really strong advocate of using Deleuze, as you know, in my teaching and learning, I just think it's so important because each concept is a new event....and so therefore, in a sense you can argue that the creation of concepts in that respect is about 'lines of flight'. If you're in some group, some assemblage, where you're engaged in discussion, you're considering the way 
forward, offering a concept, or a conceptualisation, is likely to be some kind of 'line of flight', it's a movement from one place to another, it's taking thinking in another direction, it's exploring the possibility that thought doesn't have to be trapped or enclosed within a particular concept or setting, it's linked to the figure of the 'rhizome' because, as you know, rhizomes exist in a subterranean sense but [they] pop nodes up all over the place and those nodes can be seen to represent new ideas, new ways of thinking, new affects, new ethical sensitivities or whatever. So I suppose thinking about it, initially 'lines of flight' was probably one of the figures that captivated me early on. In some of the translations of it 'lines of flight' also are described as 'lines of escape'...I don't think that means a running away from, but in the context of nomadic enquiry there's a sense in which I don't have to stay on the same track, I can transgress.

$\mathrm{H}$ : I think that was something that Elizabeth St Pierre talked about at a conference I was at [Summer Institute of Qualitative Research 2013], something about this kind of ability to choose not to follow the same patterns, and again, there's something very simple in that but also really powerful, you don't have to keep following the same paths or be constrained by the same modes of thinking.

K: Right, and thinking about learning development and professional development, I think that's really exciting, it's challenging and it's really exciting, and it ties in with a lot of things. Earlier, you were talking about Karen Barad and Donna Haraway, it ties in with their work which is kind of scientifically orientated - to do with diffraction and interference patterns, and the idea that if you engage in working with diffractive possibilities rather than the given of reflective practice - which purports to be a mirror on reality and therefore replicates - diffractive practices offer the potential for interfering with and going off in different directions. So I think that kind of thinking is also congruent with, for example, the way in which you can think about nomadic enquiry as a kind of de or re-territorialisation, of saying well okay, you've got a choice to go over the territory in a different kind of way, and through going over it in a different kind of way you re-territorialise it. So that's to do with power, that's to do with affect, that's to do with ethics, and it's about a reconfiguring that as a form of transgression, which changes things you know. So I think 'lines of flight' can relate to those kind of things, you know, I mean I don't know if that's how you see it, you're probably as familiar with it now as I am. 
$\mathrm{H}$ : It does feel that there's a emancipatory aspect to that concept that I found really exciting; I think it allows, or it allowed me in my own writing, not to feel that I had to follow this linear style of academic writing, it allowed me to follow the way the writing was taking me rather than me imposing a sort of linearity upon my writing... And I think in some of the work I've read by you, I particularly liked... the way the collaborative writing you and Jonathan did allowed you to explore 'lines of flight' in response to each other's writing.

K: I think that's important because maybe that collaborative work...talked not only about the, if you like, the line as an escape, like a centrifugal force where it's kind of throwing off at a tangent, which is what centrifugal forces do, we tend to think of centrifugal forces as going off at a tangent, but as a centripetal force, which is an equal and opposite force inward. I think one of the things we found in our writing, was the 'between the twoness' that Deleuze talks about it in relation to Guattari in Dialogues II (2002), for example. There is a kind of intensity there, and I think that the notion of intensity draws on and begins to animate the idea of assemblage, that it's not just like now, one person talking to another, but somehow or another there's an intensity there, there are molecular forces at play, these post-human possibilities that Barad (2007) and other people talk about, which kind of make the space of enquiry something more than it was before that coming together. So I think 'lines of flight' are about potentialities in a multi-directional sense, there's lots of crossover with these Deleuzian figures, because what comes into play here is the idea of multiplicity as well, there are multiple directions, it's not just a tangent that goes off from the edge of the circle, it's the possibility of forces within as well.

$\mathrm{H}$ : $\quad$ Again, I think that sense of multiplicity and potentiality is quite empowering, perhaps in particular in the learning development area where often we feel that we're being required to reduce things down to simple skill-sets and ways of doing things that are not to be questioned.

K: $\quad$ Yeah, I suppose the danger in that approach, and I think I know what you're talking about, is that development implies so much linearity doesn't it? It implies that kind of Hegelian idea of thesis and antithesis which will produce a new synthesis, you know that whole 'march of progress' theorising that Hegel (1956) and people have used. I know that we've got to come up with the word, but I think that there is an inference 
or implication in the use of the word 'development' which suggests that we can go in a straight line, step by step by step by step, and I think that whilst in some sense we do do that, such an approach overlooks the possibilities of digressing on the way, of taking a line of flight, taking a detour, making an enquiry which is about intensity or something of that kind rather than simply thinking, well, what's the next stage, what skills do I need to get from $A$ to $B$ ?

$\mathrm{H}$ : We're so often reduced to that, education feels like it's so often reduced to moving through stages, we even label them Stage One, Stage Two don't we? And there's a sense I think in which a lot of people working in learning development are very aware that that's not how it works, but also feel quite constrained by the demands and expectations on them to make it seem as if that's how it works.

K: Yeah, and I suppose it's a challenge, if you're using developmental frameworks, it's a real challenge to know how to, if you like, create diagrams as a means of constructing your practice, what do you make it look like, what happens next? We've talked about the Deleuzian idea of the 'fold', I mean it's a wonderful figure for talking about how you can fold in new experiences, new ideas, new words, new anything, into your consciousness, your learning, your knowledge, whatever. But equally it's so powerful in terms of what you can then learn, how you can express yourself. But those irruptions and eruptions; irruptions going in and eruptions going out, are, in many respects, so unpredictable, so that the potentiality that's obviously there and the intensities that are obviously there, offer a real challenge to curricula and lesson plans and programmes and schemes of work and so on, which are very much part and parcel of so many teaching and learning set-ups aren't they? So it's a challenge I think to manage it because, in a sense, as soon as you start to manage it, you make it something other than what it is meant to be.

$\mathrm{H}$ : In your own practice, in your own approach to teaching and learning, how do you bring those tensions to some kind of meaningful resolution?

K: You'll know the influence of, say, Laurel Richardson [and Elizabeth St. Pierre's] (1994) work 'Writing as a Method of Inquiry' and I've certainly found this working with Jonathan Wyatt. As you know we've written together lots and lots and we've had tensions, we've had issues, of a professional, of an academic, of a scholarly, of 
a personal nature, a whole range of natures, and we've worked to the idea of writing to it. Okay, we've got an issue here, we've got a problem, we can't work something out, well let's write to it, let's see what comes out? And I think that in that, what I've just described there, are the seeds of using collaborative writing as a method of inquiry, we've taken on Richardson's idea that writing is a method of inquiry and what we've tried to argue is that, through the collaborative process, you do get 'lines of flight', you do get intensities, you find that you're not simply being conceptual but there is an evaluative dimension to what you're doing, there's an ethical dimension to it, there's a lot to do with affect and so on. So I think the collaborative process, or collaborative processes, are often a way of being pedagogical, of enhancing inquiry into it, actually engaging in research, I mean I don't feel that I would have learned so much about Deleuze, I don't think I would have been able to apply so much of his work and his ideas to pedagogy and research if I hadn't worked with it collaboratively. I've looked back at some of our, my early writings with Jonathan, and some of it, in one sense was quite immature, but in another sense it was very exploratory, I mean we were trying to do something new. And in that collaborative space which we were nurturing there was a sense in which we were able, through affect, to try things out; I mean I knew that if I wrote to something that I was unsure of and shared it with him, he would respond in a way which honoured the writing perhaps, which maybe didn't get what I was trying to say but got something, so it became this very complex assemblage between us; we've called our writing 'Becoming Ken and Jonathan' as you know. So, I think that maybe that's the way I would think about collaborative practices; there's a kind of nascent fertility in there, there's the potential for escape, there's a possibility of change that's always there, and it's also acknowledging, I think, as I've already said, that it's not just about forming concepts, which obviously is really, really important, but it's also, it is strongly to do with, as they say in the book, (What is Philosophy?) it's about concept, affect and percept.

$\mathrm{H}$ : $\quad$ Yes, and I think that there does seem to be something quite powerful about opening up your writing to another in that way; allowing somebody to respond and then that whole kind of energy that's created in that writing to someone but also like some sense of what's happening between the two, as the book's called. At the workshop you ran for us in April, there was a sense in which you tried to introduce us a little bit to how that might work with the zigzag introduction and writing. I don't know if 
you want to explain a little bit about that as a method and what you were hoping to achieve.

K: I can't remember the name now, but there's an ABC of Deleuze and the Z is 'zigzag' and that was where we got the idea, and there's somewhere, I think it's at the beginning of Dialogues, where they talk about this idea of the zigzag. Jonathan and I have used it in various workshops that we've done on collaborative writing, Deleuze and collaborative writing, and I think the idea of it is not to, and again I want to borrow here from Barad (2007) because she's got this lovely reworking of interaction, and uses this idea, that there's something within the moment, within the space, which is more than the inter, which is the space between; the intraaction. So I think that why we've used zigzag as a mode of intra-action is to encourage people to talk into the space, to direct their talking about themselves to another person, to allow that to work in concept, affect, percept, whatever, and then to encourage the person in response, not simply to respond exactly to what the person was saying, but to respond in whatever way they feel is appropriate for them. So it might be through taking a line of flight; it might be focusing in on a particular word or an expression or whatever. So the idea is to promote and acknowledge 'assemblage' rather than some specific associational connection between two separate people. So because a workshop is essentially about space, it's a space where people work and get along together and engage in practical tasks and so on, we tried to use the zigzag in that kind of way, not as I say, to literally introduce 'me' in terms of the particularities of 'me', but to use it as a means of generating some sort of spatial dimension in which people can work together through a period of time. So I think that's kind of how we've tried to use it, I don't know if that makes sense.

$\mathrm{H}$ : Yes kind of, and I do remember the moment when the space for me changed was when John Hilsdon looked out of the window and talked to the space beyond the room that we were in...there was a tangible shift in what was happening within the room. And I found that quite exciting, that the energy could change so significantly.

$\mathrm{K}$ : Yeah, I mean, I think that appreciation of spatiality is really, really important, that there is something beyond the window, that there is something on the other side of the door that I've just walked through, that space isn't just an empty vessel to be 
filled. There's a guy called Nigel Thrift (2006) who talks about 'processual sensualism'; that we're always in a process where our senses are alert, so our senses have alertness in terms of the political nature of space or the social nature of space, the cultural nature of space and so on and so on and so forth. In Deleuze's book on Francis Bacon he offers some wonderful descriptions of Bacon, how Bacon is always changing things and scraping layers of paint away and then building up new layers, and it's just wonderful that there's a strong spatial reference to his work and I think you can, maybe you can borrow from that sensualism in the context of space and kind of link to it. I don't want to use the word 'development', but let's say learning, I think it's a form of learning which is not just based upon structured A to B type thinking but is actually cognisant of the space out the window, of how I felt when I turned up this morning, or how this coffee is affecting me now, because it's all kind of relevant I think really. You've attended a few writing workshops, I mean you went to Bronwyn (Davies) collective biography writing workshop, and I think there's a sense in which the writing can often open something up that may not be in terms of the concepts that might be written down, but it could be in terms of the feeling that you have about space, that you can feel easier about opening up, you can feel closer to the person sitting next to you, that it becomes a kind of multidimensional thing that moves away from what Deleuze and Guattari called the molar, which is the sense of self as a category of difference, that I'm a bloke, you're a woman, whatever, and therefore we're categories of difference, and moving the molar into the molecular, which is far more particular, which is far more about frisson and substance and perfume and touch, much more to do with sense and I have a feeling that collaborative writing, which can be promoted through the facility of say zigzag, and whatever subsequent iterations or whatever. It kind of taps into, or releases, those energies, because you know Deleuzian philosophy is about vitalism really, it's about energy, it's about seeing selves in relational space, it's about, what is it Donna Haraway (1991) said, our bodies don't end with our skin, it's a lovely simple thing, we've got so used to it now but it's really important, so if our bodies don't end with our skin, how do we tap into that? My feeling is that collaborative writing as a method of inquiry can begin to acknowledge those posthuman possibilities that are in Deleuze and others.

I was also thinking about how you were talking about reductionalism in terms of learning development. I mean, I think what relates to that is the idea of the 'body- 
without-organs' because I think in a sense what they're saying about 'body-withoutorgans' is that actually bodies are structured in particular ways. Of course bodies have organs, and they're not saying that they don't but what they're trying to say is that we have to be aware of the fact that bodies are organised in particular ways so that actually when we think of our heart, and we kind of think of our heart in a variety of different ways, you know we can think of our heart as a mechanical pump, we can think about our heart as the source of all our affect, we can think of our heart as a thing that energises and so on. So I think it's worth thinking about that notion of 'body-without-organs' in terms of the way in which we organise things and I wonder if we can think about learning in that kind of way. I mean, most models of learning are based upon behaviourist principles or cognitive principles really aren't they? Okay, they're modified by social constructivism, facilitative learning and so on, but it's a kind of tweaking you know, whereas I think there's a kind of fundamentalism, almost a kind of essentialism paradoxically in Deleuze and Guattari. Their ontology is very realist, they try to challenge the representational approaches, and what they're really trying to ask us to consider is if a body is organised in a particular way, that is based upon particular representations, as Foucault might ask, what are the conditions of possibility for that representation, what has allowed us discursively to accept those representations, to accept the way in which the body is organised? So it feels to me, in terms of working with learners, that I want to destabilise that, I don't want to say that it's wrong because it might be very good, very helpful, but I want to destabilise it and I want to encourage people to think about the 'body-without-organs', to think about how the organs, if you like, could be organised in different kinds of ways.

$\mathrm{H}$ : Yeah. I think it's perhaps one of the concepts that I find more difficult to engage with because...I always find it difficult to kind of get beyond that sense of the physical organs being organised [in that particular way] because that's the way the body works, does that make sense? Which just seems to then feed into a 'that's the way it's got to be' kind of discourse.

K: You know we've only got to look at the maps of Neolithic man and so on and so forth to see that our bodies, albeit over a long period of time, have changed. I'm quite interested at the moment in things about molecularity, you know how geckoes can hang off the ceiling, apparently it's not to do with glue, it's to do with molecular 
exchange; you know things like pheromones, perfume, all of those kinds of things suggest reorganisation, they're possibly very subtle and nuanced and full of affect and stuff, but I think that maybe if we want to make our approach to learning and teaching a bit more sophisticated, we've at least got to draw down those kinds of thinking at some time.

$\mathrm{H}$ : Yes I think this sense of the post-human is an idea that I find very exciting in terms of encouraging you to kind of engage with the world differently and that's always something that's attractive because it shifts, something shifts...

K: Yeah, so I think in terms of what you're interested in me commenting on, the use of writing and collaborative writing, I have a feeling that when I encourage, or when Jonathan and I collaboratively encourage people, students, participants, in workshops whatever, to write, a shift happens, and it's not irrespective of, but it doesn't matter so much what is written, it's the fact that writing has been done, and I think the fact that writing has been done shifts the space, there's a 'processual sensualism' there, there is the kind of nurturing of moments where the 'assemblage' shifts where the notion of group becomes redundant and the notion of 'assemblage' becomes much more meaningful in relation to the space. Somehow or other the writing does something and as l've said, it's less significant what the writing says, more what it animates. What it animates in terms of the space.

$\mathrm{H}$ : I think that there was a really powerful sense of that happening at the collaborative writing workshop that Bronwyn Davies ran, that it was just...tangible. And when you talk about the kind of molecular connections, it was in the air, it was like a tangible energy that was released.

K: And I think it shifts one into that space of possibility where you can begin to talk in quite valid and reasonable ways about energy, about force, about vitalism. I mean Bronwyn's written a really interesting paper comparing Deleuze and Guattari with Zen Buddhism, and it's really interesting how those crossovers are very evident, which is very much about acknowledgement but also an animation of space. So, whether there's a space for what we're talking about here in terms of learning development...? 
$\mathrm{H}$ : I think the notion of space is very relevant to learning development and there has been quite a lot written on the jiscmail about the kind of spaces that learning developers occupy within the university...

$\mathrm{K}: \quad$...or maybe spaces that they create.

\section{Afterword}

I began my interview with Ken by admitting that I had only recently bought Deleuze and Guattari's (1988) seminal 'A Thousand Plateaus'. It is a book which I have taken out of the university library many, many times, though I have rarely got beyond reading and rereading the first chapter. Every time I encounter those same lines of fizzing, dazzling prose, I find it as challenging and as difficult as ever. I often have a sensation akin to seasickness as I read but, like Ken, I always 'get' something different. I went back to that first chapter again while attempting to write this piece, and this time I was struck by Deleuze and Guattari's refusal from the very outset to define a book as a place where meaning can be found:

We will never ask what a book means as signified or signifier; we will not look for anything to understand in it. We will ask what it functions with, in connection to what other things it does or does not transmit intensities, in which other multiplicities its own are inserted and metamorphosed, and with what bodies without organs it makes its own converge. (Deleuze and Guattari, 1988, p.2).

'Rhizome', 'intensities', 'multiplicities', 'body without organs', Deleuzian concepts are troubling and troublesome, but they are not meant to be 'explained' or even 'understood': as Deleuze and Guattari themselves write, 'concepts are not waiting for us ready-made, like heavenly bodies. There is no heaven for concepts' (1994, p.2).

However, Deleuzian concepts are meant to be practical too. They can provide a 'toolbox' which can help us to think differently and, as Elizabeth St. Pierre argues, finding ways to think differently is imperative in these challenging times: 
We are in desperate need of new concepts, Deleuzian or otherwise, in this new educational environment that privileges a single positivist research model with its transcendent rationality and objectivity and accompanying concepts such as randomization, replicability, generalizability, bias and so forth - one that has marginalized subjugated knowledges and done material harm at all levels of education. (St. Pierre, 2004, p.286)

So how can we apply Deleuze to the learning development context? While concepts such as the 'nomad', the 'rhizome' and 'lines of flight' may defy rigid or fixed definition, I think they can still offer exciting and challenging lenses with which we can problematize the complex and often contradictory ways in which Learning Developers are positioned. For example, when I 'plug into' Deleuze's 'circuits', I find that the concept of the 'nomad' helps me consider what it means to wander, as Learning Developers often do, across the (higher education) landscape, sometimes on the margins, sometimes welcomed (albeit temporarily) into the heart of institutional 'territory'. Deleuze and Guattari theorise the spaces we occupy as 'striated' and 'smooth', striated spaces being those that are 'hierarchical, rule-intensive, strictly bounded and confining' (Tamboukou, 2012, p.276), spaces which have already been 'territorialized' and where the pathways are deeply furrowed. And while in a professional context we may feel compelled and constrained by particular 'striations', that is the kind of 'well-trodden' discourses that insist on framing higher education in particular ways, Deleuze and Guattari (1988, p.474) argue that 'there are always forces of deterritorialisation, lines of flight, that shatter segmentarities and open up smooth spaces that are unmarked, dynamic and create conditions of possibility for transformations to occur'.

St. Pierre suggests that it is the 'nomad' who has the ability also to 'deterritorialize space that has been territorialized, charted, ordered, and then shut down' (1997, p.412) and I think this is also what the Learning Developer has the potential to do. For me, learning development is all about opening up new spaces in which learning can happen better, or at least differently. It is about creating the kinds of 'smooth' spaces where students and academics can explore their interconnectedness, and where notions of what constitutes knowledge and knowledge transfer can be troubled, challenged and transformed. 


\section{References}

Barad, K. (2007) Meeting the universe halfway: quantum physics and the entanglement of matter and meaning. London: Duke University Press.

Deleuze, G. and Guattari, F. (1988) A thousand plateaus. London: Athlone Press Ltd.

Deleuze, G. and Guattari, F. (1994) What is philosophy? Translated by Graham Burchell and Hugh Tomlinson, London: Verso.

Deleuze, G. and Parnet, C. (2002) Dialogues II. London: Continuum.

Gale and Wyatt (2009) Between the two: A nomadic inquiry into collaborative writing and subjectivity. Cambridge: Scholars Publishing.

Haraway, D. (1991) 'A cyborg manifesto: science, technology, and socialist-feminism in the late twentieth century', in Haraway, D. (ed.) Simians, cyborgs and women: the reinvention of nature. London: Free Association Books, chapter eight, pp. 149-181.

Hegel, G. (1956) Lectures on the philosophy of world history. Translated by John Sibree. New York: Dover.

Richardson, L. and St. Pierre E. (1994) 'Writing: a method of inquiry' in Denzin, N. and Lincoln, S. (eds.) The handbook of qualitative research. Sage. pp. 959-978

St. Pierre (2004) 'Deleuzian concepts for education: the subject undone', Educational Philosophy and Theory, 36(3), pp. 283-296.

St. Pierre, E. (1997) 'Circling the text: nomadic writing practices', Qualitative Inquiry, 3(4), pp.403-417.

Tamboukou, M. (2012) 'Heterotopic and holey spaces as tents for the nomad: rereading Gwen John's letters', Gender, Place and Culture, 19(3), pp. 275-290.

Thrift, N. (2006) 'Space', Theory, Culture and Society, 23(2-3), pp. 139-155. 


\section{Author details}

Ken Gale is a lecturer in post-16 education. Ken works in the Institute of Education at Plymouth University. His main teaching and research interests can broadly be contextualised within the philosophy of education. More specifically, he is interested in the spaces of inquiry that open up when the work of post structural theorists, in particular Deleuze, and Deleuze and Guattari, but also Foucault, Derrida, Butler and Irigaray. Ken's collaborative and performative teaching and research practices connect with narrative and autoethnographic forms of inquiry and he works to apply these to theory/practice or conceptual/contextual relations as a means of exploring and inquiring into a number of areas of interest, including subjectivity, friendship, gender, teaching and learning, and professional identity and practice style.

Ken has published widely and presented at a number of international conferences. He was part of a funded project to develop online resources on collaborative writing for early career researchers and faculty: www.writeinquiry.org . With Bronwyn Davies, Susanne Gannon and Jonathan Wyatt he co-authored the book, Deleuze and Collaborative Writing: An Immanent Plane of Composition (Peter Lang, 2011) and, recently, with friends and colleagues Jonathan Wyatt, Tami Spry, Ron Pelias and Larry Russell, he has co-authored the book How writing touches: an intimate scholarly collaboration which has recently been published by Cambridge Scholars Publishing. More recently, with Jonathan Wyatt, he has edited a Special Edition on collaborative writing for the journal International Review of Qualitative Research, published in early 2013. He is an associate member of the Higher Education Academy, a member of the International Association of Qualitative Inquiry and the Narrative Inquiry Centre at the University of Bristol, where he is also a Visiting Fellow.

Ken has three children, Katy, Reuben and Phoebe, has recently become a grandfather to Rohan James and lives, nurtures and sustains his soul in Cornwall in the UK. 
Helen Bowstead is a Learning Development Advisor and member of the Learning Development team at Plymouth University. She also works part-time as an EFL lecturer. Helen is interested in narrative approaches to educational research and writing as a method of inquiry. Her most recent research project was an auto/ethnographical exploration of the impact of the internationalisation agenda and she has presented at a number of conferences on this theme including Discourse Power Resistance 2013. She has previously published two articles in the Journal of Learning Development in Higher Education (Teaching English as a Foreign Language and Coming to Writing) and she has recently contributed a chapter to a forthcoming collected edition entitled 'Working with Academic Literacies: research, theory, design' edited by Theresa Lillis, Kathy Harrington, Mary Lea and Sally Mitchell.

Helen is particularly interested in exploring barriers to effective student writing and developing pedagogical approaches that encourage written confidence and fluency. She is currently working on a project with LD colleagues to open an on campus 'Writing café'. 